\title{
High Frequency Chest Wall Compression in Cats with Normal Lungs
}

\author{
F. G. EYAL, Z. HAYEK, J. ARMENGOL, AND RICHARD JONES \\ Department of Pediatrics and Department of Pulmonary Medicine, University of Alberta, Edmonton, Alberta, \\ Canada
}

\begin{abstract}
Ten anesthetized, paralyzed adult cats were ventilated by high frequency chest wall compression (HFCWC) at 3, 5, 7, and $9 \mathrm{~Hz}$ by means of a single chamber cuff enclosing the thorax from the axillae to the xyphisternum. The effects of HFCWC in terms of gas exchange, end-expiratory lung volume, and respiratory system compliance were compared to conventional intermittent positive pressure ventilation (IPPV) $(30$ breaths $/ \mathrm{mn})$. HFCWC and IPPV were compared at three levels of matched end-expiratory airway pressure [continuous positive airway pressure (CPAP)/positive end-expiratory pressure/(PEEP) of 0,2 , and $5 \mathrm{~cm} \mathrm{H}_{2} \mathrm{O}$. In the absence of CPAP, HFCWC resulted in a marked decrease (up to $50 \%$ ) in end-expiratory lung volume with significantly lower $\mathrm{PaO}_{2}$, lower compliance, and higher alveolar-arterial oxygen gradient than during IPPV. No differences in $\mathrm{PaO}_{2}$ and $\mathrm{a}-\mathrm{ADO}_{2}$ were observed when $\mathrm{HFCWC}$ was combined to $\mathrm{CPAP} \geq 2 \mathrm{~cm} \mathrm{H}_{2} \mathrm{O}$. At frequencies below $9 \mathrm{~Hz}, \mathrm{PaCO}_{2}$ became significantly lower during $\mathrm{HFCWC}+\mathrm{CPAP}$ than during IPPV. During HFCWC $+2 \mathrm{~cm} \mathrm{H}_{2} \mathrm{O}$ CPAP, lung volume was lower than during IPPV $+2 \mathrm{~cm} \mathrm{H}_{2} \mathrm{O}$ and similar to the volumes observed during IPPV +0 positive end-expiratory pressure. Additional studies in six cats at HFCWC $+3 \mathrm{~cm} \mathrm{H} \mathrm{H}_{2} \mathrm{O}$ confirmed that CPAP $>2 \mathrm{~cm} \mathrm{H} \mathrm{H}_{2} \mathrm{O}$ more than adequately compensated the decrease in lung volume associated with HFCWC alone. Peak cuff pressures between 14 and $17 \mathrm{~cm} \mathrm{H}_{2} \mathrm{O}$ generated oscillary tidal volumes between 4.5 and $2.1 \mathrm{ml} / \mathrm{kg}$. The size of the oscillatory volume was significantly affected by increasing frequencies (decrease in tidal volume) and increasing levels of positive airway pressure (increase in tidal volume). We conclude that in cats with normal lungs, HFCWC can provide for normal gas exchange, provided that it is combined with low level CPAP in order to prevent the occurrence of airway closure associated with HFCWC alone. (Pediatr Res 21: 183-187, 1987)
\end{abstract}

\section{Abbreviations}

HFCWC, high frequency chest wall compression HFO, high frequency oscillation IPPV, intermittent positive pressure ventilation CPAP, continuous positive airway pressure VT, tidal volume FRC, pulmonary functional residual capacity VL, end-expiratory lung volume

Received September 30, 1985: accepted September 29, 1986

Correspondence and reprint address Dr. F. Eyal, Neonatal Intensive Care Unit Francis Scott Key Medical Center, 4940 Eastern Avenue. Baltimore, MD 21224

Supported by grants from Special Services and Research. University of Alberta Hospital and Research Services-Central Research Fund, University of Alberta This work was undertaken at the Surgical Medical Research Institute. University of Alberta. F.E. was on sabbatical leave from the Hadassah University Hospital, Jerusalem. Israel.

\author{
Crs, respiratory system compliance \\ Paw, airway pressure \\ Pcuff, cuff chamber pressure \\ $\mathrm{PaO}_{2}$, partial arterial oxygen pressure \\ $\mathrm{PaCO}_{2}$, partial arterial carbon dioxide pressure \\ a-ADO ${ }_{2}$, arterial-alveolar oxygen gradient \\ PEEP, positive end-expiratory pressure \\ He, helium \\ ABG, arterial blood gases
}

There are a number of modes of high frequency ventilation which provide adequate gas exchange with VT lower than the dead space. These include high frequency positive pressure ventilation, high frequency jet ventilation, and HFO, all of which are administered via the airway and thus require intubation. Recently, several investigators (1-5) have used oscillations around the chest wall (external HFO) rather than at the airway opening. Such a method may potentially avoid the use of an endotracheal tube and its associated complications $(6,7)$. In terms of gas exchange, external HFO was shown to be as efficient as the internal form (3).

External HFO has been produced by various means such as pneumatic compression in a plethysmograph $(3,4)$, high frequency negative pressure ventilation (5), and high frequency chest wall compression (2). The requirement for strict enclosure of most of the body may limit the feasibility of the first two methods in terms of its potential clinical use. Such might not be the case for high frequency chest wall compression (HFCWC) produced by means of pressure oscillations in an air filled cuff wrapped around the lower thorax. Zidulka et al. (2) showed that it was possible to ventilate, by HFCWC, paralyzed dogs with normal lungs, but at lung volumes moderately below FRC. The possibility that CPAP, combined to HFCWC, might counterbalance the deleterious effect on FRC was not addressed in that study.

This report presents the effects of HFCWC in another species whose chest wall compliance might be of greater similarity to that of a human newborn infant. The experiments were performed on paralyzed healthy cats in whom HFCWC at various frequencies, with or without CPAP, was compared to conventional positive pressure ventilation in terms of gas exchange, FRC, and lung compliance.

\section{METHODS}

Ten adult mongrel cats 2.2 to $3.0 \mathrm{~kg}$ were anesthetized with intravenous ketamine $\mathrm{HCl}(30 \mathrm{mg} / \mathrm{kg})$ and paralyzed with pancuronium bromide ( $200 \mu \mathrm{g} / \mathrm{kg}$ intravenous). These medications were repeated as necessary to maintain anesthesia and paralysis. A catheter with a Clarke $\mathrm{PO}_{2}$ electrode on its tip (G.D. Searle, Bucks, England) was inserted through the femoral artery for 
continuous $\mathrm{PaO}_{2}$ monitoring. However, full arterial blood gas measurements were periodically performed as outlined below. The catheter was maintained patent by continuous infusion of $5 \%$ dextrose in 0.2 heparinized saline at a rate of $3 \mathrm{ml} / \mathrm{kg} / \mathrm{h}$. The arterial catheter was connected to a pressure transducer (model P23db, Gould Statham Instruments Inc., Sunduan, Puerto Rico) and systemic arterial pressure and heart rate recorded. A rectal temperature probe was inserted and body temperature maintained between 37 and $38^{\circ} \mathrm{C}$ using a heating pad. In order to be able to perform measurements of FRC and respiratory system compliance, a tracheostomy was done on each animal and a tight fitting endotracheal tube was inserted and sutured in place to ensure a seal.

HFCWC was administered by means of a single chamber cuff $(30 \times 11 \mathrm{~cm})$ placed around the thorax of the cat (Fig. 1). The cuff covered the chest between the axilla and the xiphisternum. The outer membrane of the cuff consisted of stiff $4 \mathrm{~mm}$ thick rubber and the inner membrane was a thin sheet of highly distensible "dental" rubber. Two plastic tubes (1 cm ID) were inserted, through the anterior part of the outer membrane, into the cuff chamber. One was attached to a high frequency diaphragm oscillator (Metrex Instruments Ltd., Brampton, Ontario, Canada). The second tube was connected to a Valydine MP 45 differential pressure transducer with a flat frequency response to $40 \mathrm{~Hz}$. The oscillator was set to produce stroke volume between 50 and $120 \mathrm{ml}$ for the frequencies tested in this study $(3,5,7$, and $9 \mathrm{~Hz}$ ). In order to have good apposition of the soft inner rubber membrane and the chest wall, the cuff was maintained partially inflated by a bias flow of air (2-6 liter/min) fed into the tube connecting the oscillator to the cuff. An adjustable small leak was inserted at the entry of the bias flow into the connecting tube so that the minimal pressure in the cuff never exceeded 2 $\mathrm{cm} \mathrm{H}_{2} \mathrm{O}$. In those experiments where CPAP was combined to HFCWC, positive airway pressure was produced by flowing air (10 liter/min) through a $\mathrm{T}$-connector attached to the endotracheal tube and through a large bore tube placed under water to the depth of the desired CPAP (Fig. 1).

IPPV was produced by a MV-10 (Bio-Medical, Stanford, CT) pediatric pressure and time cycled ventilator. Respiratory rate and inspiratory:expiratory ratio were kept at 30 breaths/min and $1: 2$, respectively. Peak inspiratory pressure was adjusted (range 5-9 $\mathrm{cm} \mathrm{H}_{2} \mathrm{O}$ ) to allow for normocapnea. Positive and expiratory

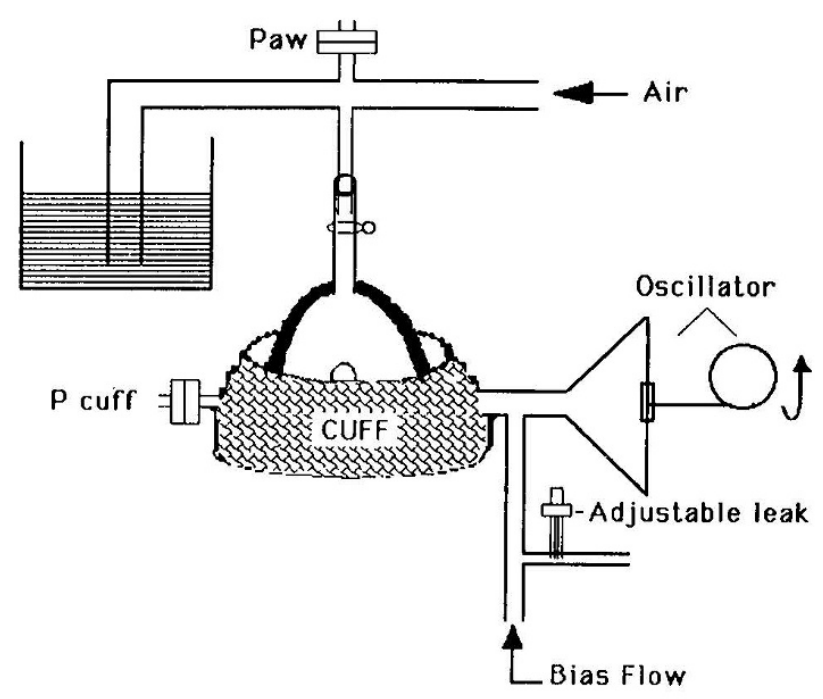

Fig. 1. Schematic diagram of the apparatus used for the delivery of HFCWC + CPAP depicting the single bladder cuff placed around the thorax connected to the pressure transducer and the oscillator. A bias flow was introduced into the tubing connecting the oscillator to the cuff to maintain apposition of the cuff around the chest wall, and small adjustments were made using the adjustable leak. pressure was set at 0,2 , or $5 \mathrm{~cm} \mathrm{H}_{2} \mathrm{O}$ to match CPAP used during HFCWC.

Thirty-min periods of HFCWC were alternated with equivalent sequences of IPPV matched for end expiratory airway pressures. The order in which the various $\mathrm{HFCWC}$ frequencies $(3,5$, 7 , and $9 \mathrm{~Hz})$ at various CPAP levels $\left(0,2\right.$, and $\left.5 \mathrm{~cm} \mathrm{H}_{2} \mathrm{O}\right)$ were studied was randomized. The stroke volume of the oscillator was kept constant for each set of experiments done with each animal. Pressures at the proximal end of the endotracheal tube and cuff chamber pressure (Pcuff) were monitored via pressure transducers (model MP $45 \pm 50 \mathrm{~cm} \mathrm{H}_{2} \mathrm{O}$, Valydine, Northridge, CA) connected to a Hewlett Packard recorder (model 37404 A, Waltham, MA). That system had a flat frequency response to $40 \mathrm{~Hz}$.

Arterial blood gases, VL, and respiratory system compliance were measured at the end of each ventilatory sequence. The alveolar arterial oxygen gradient was calculated by the following formula: $\mathrm{A}-\mathrm{aDO}_{2}=\left(\mathrm{PIO}_{2}-\mathrm{PaCO}_{2} / \mathrm{R}\right)-\mathrm{PaO}_{2}$, where $\mathrm{PIO}_{2}$ is the partial pressure of inspired oxygen. $\mathrm{R}$ was assumed to be 0.8 .

End expiratory VL was measured using a modification of the closed circuit He dilution technique (8). A 50-ml glass syringe was filled with a mixture containing approximately $10 \% \mathrm{He}$ in air. The He concentration was determined prior to each VL measurement using a He catharometer (PulmoAnalyser, Godart, DeBilt, Utrecht, Holland). The VL measurement required clamping the endotracheal tube at end expiration, and with HFCWC we found it necessary to perform up to eight clampings in order to obtain end-expiration, which was defined as the most positive cuff pressure in the oscillation cycle. When the airway was clamped at a point in the respiratory cycle other than endexpiration, the clamp was immediately released and reclamped 10 s later. When end-expiration was obtained, the oscillator was stopped and the He-containing syringe was attached to the airway and manually oscillated at approximately $2 \mathrm{~Hz}$, with a stroke volume of about $10 \mathrm{ml}$ for $30 \mathrm{~s}$. The He concentration in the syringe was determined after $30 \mathrm{~s}$ of "rebreathing" and VL calculated. We found in previous studies that $15 \mathrm{~s}$ was sufficient when the procedure is conducted as described. We have used this method repeatedly and, using a lung model, have found it both reproducible and accurate $( \pm 5 \%)$.

Total Crs was measured by stepwise inflation and deflation of the lungs from end-expiratory VL. Twenty-five $\mathrm{ml}$ of air was injected every 3-4 s until an airway pressure of $25 \mathrm{~cm} \mathrm{H}_{2} \mathrm{O}$ was achieved. Then, the air was withdrawn at similar volume and speed. Compliance was calculated as the slope of the linear portion of the deflation limb of the pressure volume curve immediately above VL.

VT was obtained during HFCWC by the reverse plethysmographic technique (3). A plexiglass chamber (plethysmograph) containing 18 liter of air and steel wool (to minimize adiabetic pressure change) was connected to the endotracheal tube by a 20 $\mathrm{cm}$ long $(0.9 \mathrm{~cm}$ ID) Tygon tube and the pressure changes in the plethysmograph were recorded during HFCWC. The pressure changes generated in the plethysmograph by the oscillatory VT were less than $1 \mathrm{~cm} \mathrm{H} \mathrm{H}_{2} \mathrm{O}$. The amplitude of the signal produced by a fixed stroke volume $(22 \mathrm{ml})$ metal bellows oscillator connected to the plethysmograph via the Tygon tube was found to be reduced by less than $3 \%$ at $30 \mathrm{~Hz}$ compared to $1 \mathrm{~Hz}$. The resonant frequency of the plethysmograph, the Valydine MP 45 differential pressure transducer, and the connecting tubing was $117 \mathrm{~Hz}$.

At a later stage, six additional cats $(2.4-3.6 \mathrm{~kg})$ were added to the present study. These animals were ventilated by only one rate of HFCWC $(5 \mathrm{~Hz})$ combined with one exclusive level of CPAP: $3 \mathrm{~cm} \mathrm{H}_{2} \mathrm{O}$. Thirty-min periods of HFCWC were alternated with periods of IPPV at 0 and $3 \mathrm{~cm} \mathrm{H}_{2} \mathrm{O}$ PEEP. At the end of each different ventilatory sequence, ABG, VL, VT, and Crs were measured as previously described. On three of the animals cardiac output was measured during HFCWC and during IPPV both at $3 \mathrm{~cm} \mathrm{H}_{2} \mathrm{O}$ PEEP. A $5 \mathrm{Fr}$ flow directed catheter was inserted and cardiac output was measured in triplicate using 
the thermodilution technique (Cardiac output computer 601 . Instrumental Laboratory Inc., Lexington, MA) with the rapid injection of $3 \mathrm{ml}$ of $\mathrm{O}^{\circ} \mathrm{C}$ normal saline into the distal port of the pulmonary artery catheter.

Statistical analysis was performed by one-way analysis of variance. When statistical significance was present, a Dunnett's multiple comparison procedure (9) was performed. Statistical significance was established at $p<0.05$. Data are presented as mean + SD.

\section{RESULTS}

Figures 2 and 3 summarize the effect on $\mathrm{PaCO}_{2}$ and $\mathrm{PaO}_{2}$ of HFCWC, compared to IPPV, at the various frequencies and levels of end-expiratory airway pressure tested in the first 10 animals.

At 0 end-expiratory pressure, mean $\mathrm{PaCO}_{2}$ was similar during IPPV and the various HFCWC frequencies. At frequencies below $9 \mathrm{~Hz}$, the combination of HFCWC and CPAP resulted in lower $\mathrm{PaCO}_{2}$ than during HFCWC alone $(p<0.01)$. There were no significant differences between the two levels of CPAP tested. The lowest mean $\mathrm{PaCO}_{2}$ (19 \pm 4 torr) was observed during $\mathrm{HFCWC}$ at $3 \mathrm{~Hz}$ and $5 \mathrm{~cm} \mathrm{H}_{2} \mathrm{O}$ CPAP. Except for the latter combination, there was no significant difference between HFCWC + CPAP and IPPV at matched PEEP. During HFCWC + CPAP, $\mathrm{PaCO}_{2}$ was lower at 3 than at $9 \mathrm{~Hz}$ frequencies $(p<$ $0.01)$.

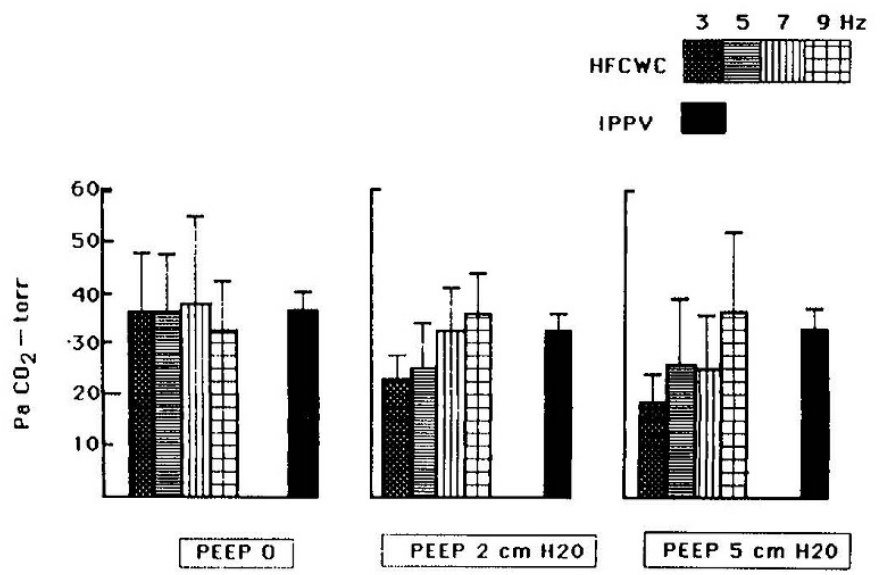

Fig. 2. Comparison of $\mathrm{PaCO}_{2}$ during IPPV and $\mathrm{HFCWC}$ at the different frequencies and levels of positive end-expiratory pressure tested $($ mean $+\mathrm{SD})$

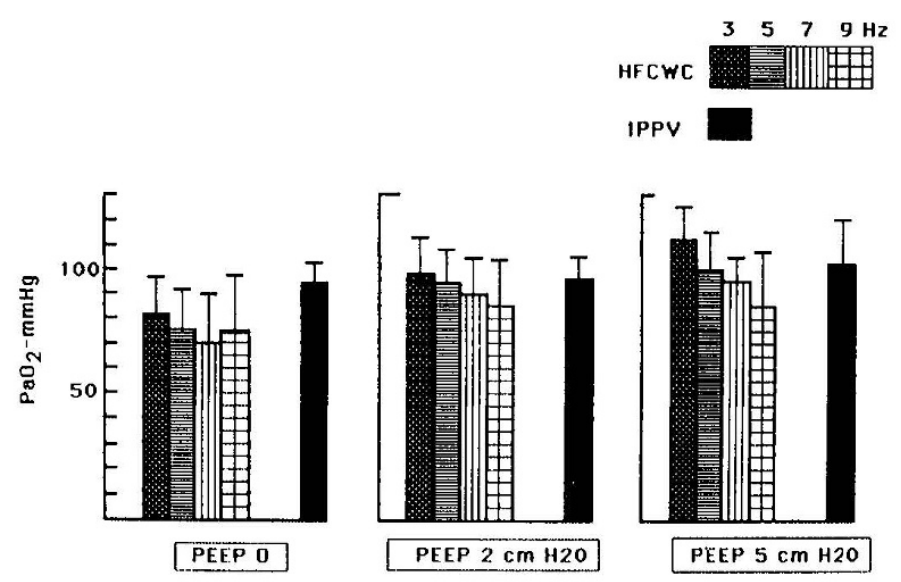

Fig. 3. Comparison of $\mathrm{PaO}_{2}$ during IPPV and HFCWC at the different frequencies and levels of positive end-expiratory pressure tested $($ mean $+\mathrm{SD})$.

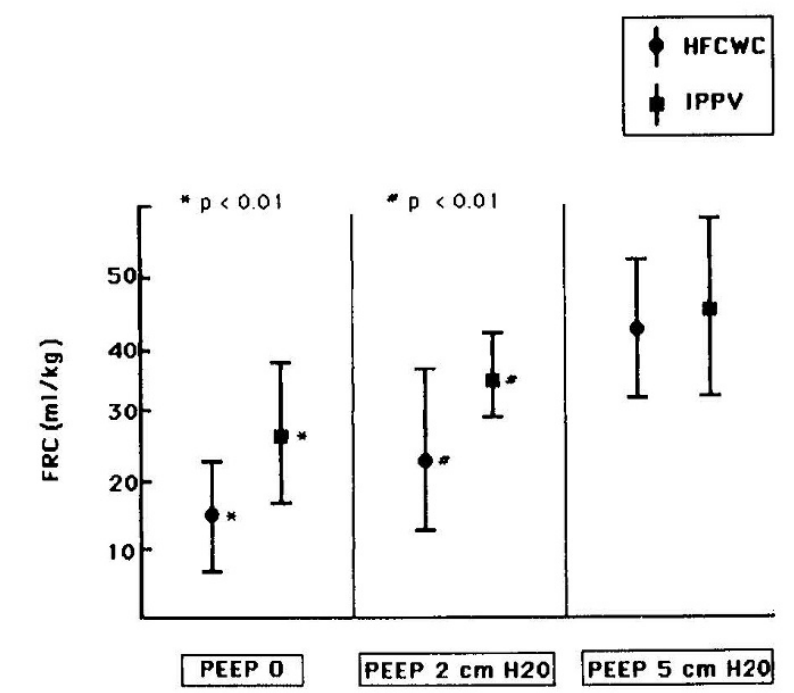

Fig. 4. Comparison of end-expiratory lung volume during HFCWC $(l e f t)$ and IPPV (right) at various levels of end-expiratory pressure (mean $\pm \mathrm{SD}$ ).

Mean $\mathrm{PaO}_{2}$ was lower during HFCWC than during IPPV at 0 end-expiratory pressure. This difference was statistically significant at frequencies above $3 \mathrm{~Hz}(p<0.05)$. The combination of HFCWC and CPAP, at both levels tested, resulted in higher $\mathrm{PaO}_{2}$ than during HFCWC alone $(p<0.01)$ and no differences were then observed between HFCWC and IPPV at matched PEEP. With CPAP, $\mathrm{PaO}_{2}$ was least improved during $\mathrm{HFCWC}$ at $9 \mathrm{~Hz}$ frequency and the difference between 3 and $9 \mathrm{~Hz}$ was statistically significant $(p<0.05)$.

Only in the absence of PEEP, was $\mathrm{A}-\mathrm{aDO}_{2}$ significantly smaller during IPPV $(8.5 \pm$ torr) than during HFCWC at frequencies above $3 \mathrm{~Hz}(p<0.01)$. The widest gradient was observed at 9 $\mathrm{Hz}(31 \pm 18$ torr $)$.

There were significant differences between VL (Fig. 4) during HFCWC and IPPV at 0 and $2 \mathrm{~cm} \mathrm{H}_{2} \mathrm{O}$ end-expiratory airway pressure $(p<0.01)$, with the lowest VL obtained on HFCWC + 0 PEEP $(14.6 \pm 8 \mathrm{mg} / \mathrm{kg})$. During IPPV + PEEP $2 \mathrm{~cm} \mathrm{H}_{2} \mathrm{O}$ mean VL was $35 \pm 6 \mathrm{ml} / \mathrm{kg}$, while HFCWC + PEEP $2 \mathrm{~cm} \mathrm{H} \mathrm{H}_{2} \mathrm{O}$ and IPPV + 0 PEEP yielded an intermediate value for VL $(23 \pm 13$ and $27 \pm 10 \mathrm{ml} / \mathrm{kg}$, respectively). There were no differences between the respective HFCWC frequencies although there was a trend for $\mathrm{VL}$ to be larger at $3 \mathrm{~Hz}$ than at the other rates during HFCWC + 0 PEEP $(17 \pm 8 \mathrm{ml} / \mathrm{kg})$.

Crs (Table 1) was lower during HFCWC than during IPPV at 0 and $2 \mathrm{~cm} \mathrm{H}_{2} \mathrm{O}$ end-expiratory airway pressure $(p<0.01)$. There were no differences between the various HFCWC frequencies. Specific compliance (compliance per unit of FRC) was similar during IPPV and HFCWC when PEEP was used.

Oscillatory tidal volumes, measured at the tracheal tube level, are shown in Figure 5. There was a significant reduction in VT with increasing frequencies from an average of $3.6 \pm 0.9 \mathrm{ml} / \mathrm{kg}$ at $3 \mathrm{~Hz}$ to $2.4 \pm 0.8 \mathrm{mg} / \mathrm{kg}$ at $9 \mathrm{~Hz}(p<0.01)$. For all frequencies, the efficiency of HFCWC in inducing VT improved with increasing level of CPAP. This effect was largest at $3 \mathrm{~Hz}(2.9 \pm 0.6$ versus $4.5 \pm 0.5 \mathrm{ml} / \mathrm{kg}$ at 0 and $5 \mathrm{~cm} \mathrm{H}_{2} \mathrm{O}$ CPAP, respectively), and minimal at $9 \mathrm{~Hz}(2.1 \pm 0.5$ versus $2.7 \pm 1.0 \mathrm{ml} / \mathrm{kg}$ at 0 and $5 \mathrm{~cm} \mathrm{H}_{2} \mathrm{O}$ CPAP, respectively).

The mean peak cuff pressure during HFCWC ranged from 14 $\pm 3 \mathrm{~cm} \mathrm{H} \mathrm{H}_{2} \mathrm{O}$ at $3 \mathrm{~Hz}$ to $17 \pm 3 \mathrm{~cm} \mathrm{H} \mathrm{H}_{2} \mathrm{O}$ at $9 \mathrm{~Hz}$, while mean peak to trough cuff pressures ranged from $13 \pm 3$ and $15.5 \pm 3$ $\mathrm{cm} \mathrm{H}_{2} \mathrm{O}$, respectively. These differences between the two extreme rates were statistically significant $(p<0.01)$.

Mean arterial blood pressure and heart rate were similar during HFCWC and IPPV. Mean systolic blood pressure was lower when end-expiratory pressure was above zero $(139 \pm 20 \mathrm{~mm} \mathrm{Hg}$ 
Table 1. Comparison of Crs and CRS/FRC during HFCWC and IPPV at various levels of end-expiratory airway pressure

\begin{tabular}{|c|c|c|c|c|c|c|}
\hline \multirow{2}{*}{$\begin{array}{c}\text { PEEP } \\
\left(\mathrm{cm} \mathrm{H} \mathrm{H}_{2} \mathrm{O}\right)\end{array}$} & \multicolumn{3}{|c|}{$\mathrm{CRS}\left(\mathrm{ml} / \mathrm{cm} \mathrm{H}_{2} 0\right)$} & \multicolumn{3}{|c|}{$\mathrm{CRS} / \mathrm{FRC}$ (liter/cm $\mathrm{H}_{2} \mathrm{O} /$ liter FRC) } \\
\hline & 0 & 2 & 5 & 0 & 2 & 5 \\
\hline HFCWC & $7.3 \pm 1.2^{*}$ & $7.1 \pm 0.8^{*}$ & $8.3 \pm 1.2$ & $0.65 \pm 0.35^{*}$ & $0.33 \pm 0.07$ & $0.22 \pm 0.05$ \\
\hline IPPV & $8.5 \pm 1.9$ & $9.0 \pm 2.2$ & $8.3 \pm 1.8$ & $0.36 \pm 0.12$ & $0.27 \pm 0.08$ & $0.21 \pm 0.14$ \\
\hline
\end{tabular}

${ }^{*} p<0.001$.
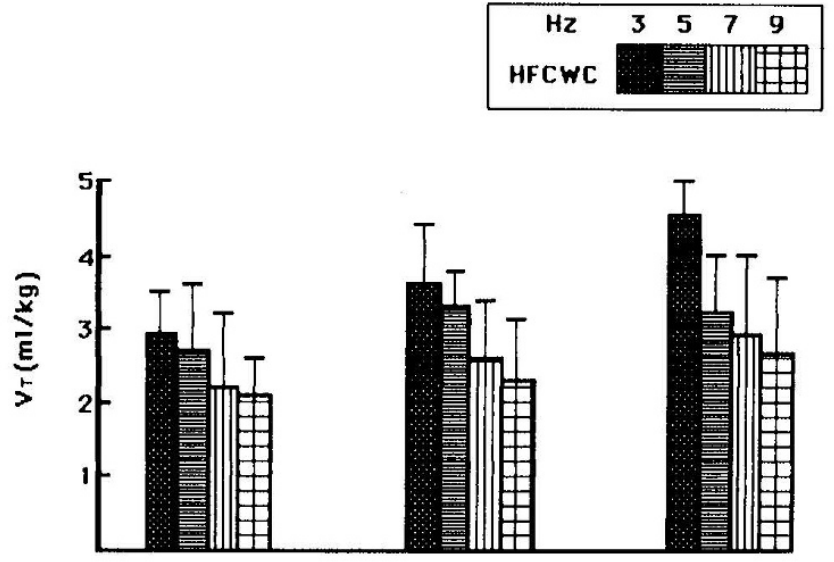

PEEP

(om H20)

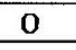

2

5

Fig. 5. Oscillatory tidal volume during HFCWC. Effects of different frequencies and different levels of CPAP (mean $+\mathrm{SD})$.

Table 2. Comparison of $\mathrm{HFCWC}(5 \mathrm{~Hz})+3 \mathrm{~cm} \mathrm{H} \mathrm{H}_{2} \mathrm{OCPAP}$ and IPPV $+3 \mathrm{~cm} \mathrm{H}_{2} \mathrm{O} P E E P$

\begin{tabular}{|c|c|c|c|c|c|}
\hline & $\begin{array}{l}\mathrm{PaCO}_{2} \\
\text { (torr) }\end{array}$ & $\begin{array}{l}\mathrm{PaO}_{2} \\
\text { (torr) }\end{array}$ & $\begin{array}{c}\mathrm{A}-\mathrm{aDO}_{2} \\
\text { (torr) }\end{array}$ & $\begin{array}{c}\mathrm{VL}^{*} \\
(\mathrm{ml} / \mathrm{kg})\end{array}$ & $\begin{array}{c}\text { CRS } \\
\left(\mathrm{ml} / \mathrm{cm} \mathrm{H}_{2} \mathrm{O}\right)\end{array}$ \\
\hline HFCWC & $20 \pm 2$ & $100 \pm 12$ & $19 \pm 6$ & $35 \pm 9.5$ & $7.7 \pm 1.6$ \\
\hline IPPV & $37 \pm 5$ & $91 \pm 7$ & $11 \pm 7$ & $42 \pm 9.5$ & $9.1 \pm 1.9$ \\
\hline
\end{tabular}

$* p<0.005$.

at 0 PEEP versus $130 \pm 20$ and $126 \pm 23 \mathrm{~mm} \mathrm{Hg}$ at 2 and $5 \mathrm{~cm}$ $\mathrm{H}_{2} \mathrm{O}$, respectively; $p<0.01$ ).

Data from the six cats comparing IPPV + PEEP to HFCWC $(5 \mathrm{~Hz})+$ CPAP at a similar end-expiratory pressure are presented in Table 2. $\mathrm{PaCO}_{2}$ decreased significantly with $\mathrm{HFCWC}(p<$ 0.005 ), the lowest $\mathrm{PaCO}_{2}$ achieved was 11.7 torr. There were significant differences between VL during IPPV + PEEP $3 \mathrm{~cm}$ $\mathrm{H}_{2} \mathrm{O}(42.4 \pm 9.5 \mathrm{ml} / \mathrm{kg})$, HFCWC + CPAP $3 \mathrm{~cm} \mathrm{H} \mathrm{H}_{2} \mathrm{O}(35 \pm 9.6$ $\mathrm{ml} / \mathrm{kg})$, and IPPV + 0 PEEP $(30.4 \pm 7.7 \mathrm{ml} / \mathrm{kg})(p<0.001)$.

Cardiac output was measured in only three cats. There were no differences between the mean cardiac output on HFCWC (5 $\mathrm{Hz})+3 \mathrm{~cm} \mathrm{H} \mathrm{H}_{2} \mathrm{O}$ CPAP and IPPV $+3 \mathrm{~cm} \mathrm{H}_{2} \mathrm{O}$ PEEP in those animals ( $267 \pm 93$ versus $288 \pm 64 \mathrm{ml} / \mathrm{min}$, respectively).

\section{DISCUSSION}

This study confirms the results of Zidulka et al. (2) who demonstrated that it is possible to ventilate anaesthetized paralyzed animals with normal lungs by high frequency chest wall compression. In addition, we demonstrated that lung volume can be maintained by the application of $2-3 \mathrm{~cm} \mathrm{H}_{2} \mathrm{O}$ CPAP.

There are a number of possible explanations why we were able to achieve adequate gas exchange with cuff pressures six to seven times lower than in the study of Zidulka et al. (2). In the latter study, in dogs, peak cuff pressures up to $230 \mathrm{~cm} \mathrm{H}_{2} \mathrm{O}$ were required to generate oscillatory tidal volume which, per unit of body weight, were of equal magnitude to those measured in our experiments. One factor may be due to the differences in species with possible less attenuation of the pressure from the chest wall to the lung in cats. The differences in chest wall compliance between cats $(3.9 \mathrm{mg} / \mathrm{kg})$ and dogs $(2.5 \mathrm{ml} / \mathrm{kg})(10)$ are likely to be too small to account for the marked discrepancy between cuff pressure requirement between the two species. A second factor may be the use of a different technique regarding the type of cuff and the manner in which the cuff was apposed to the chest. By designing a single chamber cuff enclosing the entire lower thorax, with an outer membrane of stiff, poorly compliant rubber and thin distensible rubber on the inner surface, we were able to achieve good apposition with the bias flow, without constricting the chest wall. Also, there was no bulging of the outer membrane, a difficulty encountered by Zidulka et al. (2), who used a double blood pressure cuff positioned on either side of the rib cage, with an outer membrane made of canvas. This outward bulge, which allowed for a large portion of the pumped-in volume not to be used efficiently toward squeezing the chest wall, as well as the relatively poor compliance of their cuff, were the most likely causes for the higher cuff pressure needed byc'Zidulka et al. (2) to achieve adequate displacement of the chest wall. It appeared that increasing peak cuff pressure up to a certain point (usually $25 \mathrm{~cm} \mathrm{H}_{2} \mathrm{O}$ ) was associated with adequate gas exchange, whereas above this pressure there was a deterioration in gas exchange.

One of the major concerns of HFCWC is the associated reduction in lung volume with the application of positive pressure to the chest wall. This decrease in lung volume was observed by Zidulka et al. (2) in their study on dogs in which they showed, using a pneumotachograph, that end-expiration with HFCWC occurred at $80-100 \mathrm{ml}$ below the paralyzed FRC (zero airway pressure), producing an estimated fall of $10 \%$ in FRC. Some differences in end-expiratory volume can be expected when comparing IPPV, where end-expiratory volume is achieved at the resting position of the respiratory system, and HFCWC where end-expiratory volume at end compression of the chest wall is below the same resting position. Nevertheless the differences should be equal to the oscillatory VT, i.e. approximately $3 \mathrm{ml} /$ $\mathrm{kg}$. In our study we observed that lung volume, determined by the He dilution technique, decreased up to $50 \%$ once HFCWC without CPAP was applied to cats with normal lungs. This marked decrease in FRC, resulting in airway closure, could have been due to constriction of the chest wall by our cuff system. In this study, we used a variable stroke volume pump so that we were able to alter peak cuff pressure without increasing the bias flow, thus lessening the risk of constricting the chest wall. In preliminary experiments, we measured the pressure load applied to the chest wall with a wafer transducer (11) situated below the cuff. When apposition of the cuff was produced by the bias flow and the variable leak in such a manner that minimal cuff pressure did not exceed $2 \mathrm{~cm} \mathrm{H}_{2} \mathrm{O}$ (as performed in our experiments), no pressure load was measured at the chest surface at the end of the outward chest wall recoil. On the other hand, inadvertent constriction (similar in a reverse way to "inadvertent" PEEP) (12) can occur if the passive outward recoil of the chest wall requires more time to be completed than its active inward displacement. The observation made by Zidulka et al. (2) that peak expiratory flow at the mouth were significantly greater than peak inspiratory flow, illustrates the probable different time constant for inward (active) and outward (passive) displacement of the chest during HFCWC. As observed in our study, this will result in FRC to be 
lowest for shortest deflation time (i.e. at $9 \mathrm{~Hz}$ ) and to be least affected with the more prolonged times (i.e. at $3 \mathrm{~Hz}$ ). As opposed to dogs, a greater degree of "inadvertent" constriction is also to be expected in cats who, because of their more compliant rib cage, are likely to have, during HFCWC, proportionally larger inward excursion of the chest wall. The cuff inflation: deflation time ratio was $1: 1$ and could not be changed as the oscillator we used generated a sinusoidal pressure waveform. We were therefore unable to assess the possibility that longer deflation than inflation time might lessen the decrease in FRC associated to HFCWC. In the present study we have shown that VL during $\mathrm{HFCWC}+\mathrm{CPAP}>2 \mathrm{~cm} \mathrm{H}_{2} \mathrm{O}$ is greater than $\mathrm{VL}$ at zero endexpiratory on IPPV, indicating that the combination of HFCWC + CPAP more than adequately compensated the decrease in VL associated with HFCWC alone. Also, HFCWC + CPAP, for similar cuff pressures, generated larger oscillatory VT than during HFCWC which indicates that the chest-lung outward recoil was of larger amplitude with the former combination. This "facilitated" outward recoil counteracting the tendency for "inadvertent" chest constriction is the likely mechanism by which CPAP preserves FRC during HFCWC.

Once that airway closure was prevented by the use of CPAP, there were no significant differences in the levels of $\mathrm{PaO}_{2}$ and $\mathrm{PaCO}_{2}$ reached by $\mathrm{HFCWC}$ at 3,5 , or $7 \mathrm{~Hz}$. On the other hand, for a similar increase in $\mathrm{VL}$ and compliance, there was no significant improvement in $\mathrm{PaCO}_{2}$ and $\mathrm{PaO}_{2}$ when $\mathrm{HFCWC}$ at $9 \mathrm{~Hz}$ was combined with CPAP. This could possibly be because, at the latter rate, cuff deflation (inspiration) time becomes too short to allow the generation of VT of sufficient size. Similarly, Zidulka et al. (2) observed that HFCWC above $8 \mathrm{~Hz}$ failed to produce normoventilation in paralyzed dogs. The decreased ability to ventilate by HFCWC at those highest rates could also be related to the damping of the oscillatory energy from the chest wall to the alveoli. It has been calculated that in cats (13), the wave amplitude from chest wall to alveoli would be attenuated by $20 \%$ at $5 \mathrm{~Hz}$ and $50 \%$ at $10 \mathrm{~Hz}$. Possibly this attenuation, which might differ for each species and between normal and sick lungs, could be a major factor in the ability to ventilate by external HFO.

The degree by which FRC will be reduced during HFCWC is likely to be inversely related to the compliance of the chest wall. In dogs and in healthy human adults (14), for whom chest wall compliance is lower than in cats, HFCWC resulted in minor decrease in FRC (10 and 5\%, respectively). Normal gas exchange was obtained with isolated HFCWC. On the other hand, in species with a more compliant rib cage (i.e. cats, rabbits, and newborn infants), HFCWC requires combination with moderate amount of CPAP to prevent a major decrease in FRC and airway closure. This has been recently confirmed by Piquet et al. (15) who demonstrated that rabbits subjected to high-frequency body surface oscillation became hypoxemic unless external HFO was combined with $5 \mathrm{~cm} \mathrm{H}_{2} \mathrm{O}$ CPAP.

HFCWC can provide for normoventilation with VT close to or below dead space volume similar to other techniques of HFO
(16). In spontaneously breathing human adults, the superimposition of HFCWC resulted in a $40 \%$ decrease in spontaneous minute ventilation without changes in $\mathrm{PaCO}_{2}$ (17). This enhanced gas mixing produced by HFCWC might also increase effective alveolar ventilation during IPPV. If this is so, the combination of HFCWC and IPPV and PEEP could allow for positive pressure ventilation of lesser intensity and decrease risks of barotrauma.

Further pathologic studies, such as in the surfactant depleted lungs, are necessary to determine the ultimate role of HFCWC.

Acknowledgments. The authors thank Dr. David Schiff for his tremendous support, Dr. R. King and N. Feiner for their insightful suggestions, Prof. S. Godfrey and Dr. M. Grunstein for the critical review of the manuscript, and Ms. C. Merkel for technical assistance.

\section{REFERENCES}

1. Ward HE, Power JHT, Nicholas TE 1983 High-frequency oscillations via the pleural surface: an alternative mode of ventilation? J Appl Physiol 54:427433

2. Zidulka A. Gross D, Minami H, Vartian V, Chang HK 1983 Ventilation by high-frequency chest wall compression in dogs with normal lungs. Am Rev Respir Dis 127:709-713

3. Harf A, Bertrand C, Chang HK 1984 Ventilation by high-frequency oscillation of thorax or at trachea in rats. J Appl Physiol 56:155-160

4. Ward HE, Armengol J, Jones RL 1985 Ventilation by high frequency oscillation in cats. J Anpl Physiol 58:1390-1399

5. Eyal FG, Hayek Z, Armengol J, Jones RL 1986 Comparison of high frequency negative pressure oscillation with conventional mechanical ventilation in normal and saline-lavaged cats. Crit Care Med 14:724-729

6. Joshi VV, Mandavia SG, Stern L, Wigglesworth FW 1972 Acute lesions induced by endotracheal intubation. Occurrence in the upper respiratory tract of newborn infants with respiratory distress syndrome. Am J Dis Child 124:646-649

7. Phelps DL, Loew DA, Oh W 1974 The laryngo-tracheal function of surviving infants following prolonged oro-tracheal intubation during the neonatal period. Clin Res 22:242

8. Meneely GR, Kaltreider NL 1941 Use of Helium for the determination of pulmonary capacity. Proc Soc Exper Biol Med 46:266

9. Winer BJ 1971 Statistical Principles in Experimental Design. McGraw-Hill, New York, pp 201-204

10. Spells KE 1969/70 Comparative studies in lung mechanics based on a survey of literature data. Respir Physiol 8:37-57

11. Hoppin FG Jr, Green ID, Mead J 1969 Distribution of pleural surface pressure in dogs. J Appl Physiol 27:863-873

12. Peppe PE, Marine JJ 1982 Occult positive end expiratory pressure in mechanical ventilation in patients with airflow obstruction. The auto PEEP effect. Am J Res Dis 126:166-170

13. Brody AW, DuBois, AB, Nissel OI 1956 Natural frequency, damping factor and inertance of the chest-lung system in cats. Am J Physiol 186:142-146

14. Harf A, Zidulka A, Chang HK 1985 Nitrogen washout during tidal breathing with superimposed high frequency chest wall oscillation. Am Rev Respir Dis 132:350-353

15. Piquet J, Isabey $\mathrm{D}$, Chang $\mathrm{KH}$, Harf A 1985 Stable normocapnia during highfrequency body surface oscillation in rabbits. Am Rev Respir Dis 132:104108

16. Drazen JM, Kamm RD, Slutsky AS 1984 High-frequency ventilation Physiol Rev 64:505-543

17. Calverley PMA, Chang HK, Vartian V, Zidulka A 1986 High frequency ches wall oscillation assistance to ventilation in spontaneously breathing subjects. Chest 89:218-223 